\title{
MPL NP_005364.1:p.W515L
}

National Cancer Institute

\section{Source}

National Cancer Institute. MPL NP 005364.1:p.W515L. NCI Thesaurus. Code C126824.

A change in the amino acid residue at position 515 in the thrombopoietin receptor protein where tryptophan has been replaced by leucine. 